\title{
Visualizing Mismatches in Pronunciation among EL2 Chinese Learners at Segmental Level ${ }^{*}$
}

\author{
Chao $\mathrm{Wu}$ \\ Nanchang Business College, Jiangxi Agricultural University, Jiangxi, China \\ Qiufeng Pan \\ Nanchang Business College, Jiangxi Agricultural University, China \\ Daiyue Cao \\ Nanchang Mengchong Education Consulting Co., Ltd, China
}

\begin{abstract}
In our pronunciation courses, segmental level in English pronunciation plays a very important role in perception and teaching of English pronunciation. This research aims to investigate into the most salient pronunciation problems at segmental level by fresh college students from Mainland China through an experimental study, and it is found that the mismatches identified in the segmental level of English pronunciation are corresponded with the phonological features of the utterance of Chinese English. Moreover, in order to improve fresh college student' pronunciation and achieve the pronunciation of Standard English, some pedagogical implications and suggestions about teaching strategies are provided in this study which aimed at the most salient mismatches discovered in the research findings.
\end{abstract}

Index Terms —English pronunciation, segmental level, implications for teaching

\section{INTRODUCTION}

Foreign language (FL) learners' mispronunciations are not random, as a foreign accent produced by learners largely reflects the phonetic features and intonation characteristics of their first language (L1) (Avery \& Ehrlich, 1992; Ohata, 2004; Swan \& Smith, 1987), Chinese EFL learners are inclined to confront these phonetic features or challenges in pronunciation which involve certain individual vowels and consonants, and these English phonetic features do not occur in Chinese pronunciation or are uttered differently in Chinese ( Table 1), so consequently native Chinese EFL learners who cannot overcome these obstacles find it hard to speak pure, native-like English.

TABLE 1

CONSONANT Phonemes Of English. COLORED Phonemes ARE Not SHAREd With Chinese

\begin{tabular}{|c|c|c|c|c|c|c|c|c|}
\hline $\begin{array}{l}\text { MOA } \\
\text { POA }\end{array}$ & $\begin{array}{l}\text { Both lip } \\
\text { /bilabial }\end{array}$ & $\begin{array}{l}\text { Lower lip } \\
\text { and upper } \\
\text { teeth } \\
\text { /labiodental }\end{array}$ & \multicolumn{2}{|c|}{$\begin{array}{c}\text { Tip of } \\
\text { tongue and } \\
\text { teeth } \\
\text { /interdental }\end{array}$} & $\begin{array}{l}\text { Tip of tongue and tooth ridge } \\
\text { /apicoalveolar }\end{array}$ & $\begin{array}{c}\text { Front of tongue and hard palate } \\
\text { /laminopalatal }\end{array}$ & $\begin{array}{c}\text { Back of } \\
\text { tongue } \\
\text { and soft } \\
\text { palate } \\
\text { dorsovelar }\end{array}$ & $\begin{array}{l}\text { Throat } \\
\text { /glottal }\end{array}$ \\
\hline \multirow{2}{*}{ stops } & voiceless & $\mathrm{p}$ & & & $\mathrm{t}$ & & $\mathrm{k}$ & \\
\hline & voiced & $\mathrm{b}$ & & & $\mathrm{d}$ & & $\mathrm{g}$ & \\
\hline \multirow{2}{*}{ affricates } & voiceless & & & & & t & & \\
\hline & voiced & & & & & ds & & \\
\hline \multirow{2}{*}{ fricatives } & voiceless & & $\mathrm{f}$ & $\theta$ & $\mathrm{s}$ & $\int$ & & $\mathrm{h}$ \\
\hline & voiced & & $\mathrm{v}$ & ð & $\mathrm{z}$ & 3 & & \\
\hline nasals & $\mathrm{m}$ & & & & $\mathrm{n}$ & & & \\
\hline lateral & & & & & 1 & & & \\
\hline semivowels & $\mathrm{W}$ & & & & $\mathrm{r}$ & $\mathrm{j}$ & & \\
\hline
\end{tabular}

Notes: POA and MOA refer to place of articulation and manner of articulation respectively.

The segmental features of English speech (e.g. consonants, vowels, etc.) play an important part in the speakers' appropriate pronunciation of English, which can be considered as the major elements in English language pronunciation. Moreover, there are still a large number of Mandarin speakers who keen on studying English nowadays in China. What's more, with years' experience of English pronunciation teaching, the author has perceived it is worthwhile exploring the features of English pronunciation in segmental level by college students from Mainland China. So, the present study will give specific attention to the discussion of this problem in an experimental way. Hence, this paper detects the pronunciation errors at segmental level of ten college students who come from different parts of mainland China (Northeast, Central and Eastern China), and a sound experiment implements through acoustic phonetic software,

\footnotetext{
* This research was funded by 2020 "13th Five-Year Plan" Project of Jiangxi Educational Science. (Project No: 20YB355)
} 
praat. Furthermore, comparisons will also be made between perception and pronunciation experiment results because of the relationship between these two factors in the acquisition process. Hopefully this study will provide English teachers suggestions about teaching strategies aiming at the most salient problems while teaching English.

\section{LITERATURE REVIEW}

The pronunciation of Cantonese English spoken by people from Guangdong Province and Hong Kong has a large number of research findings already. However, as Deterding (2006) claimed, there were few researches into the English pronunciation features among the Mandarin speakers. And lots of researches only focus on analyzing the utterance features from accents of Hong Kong and Guangdong province, no discussion of the English pronunciation of speakers come from other parts of China. In previous researches on the English pronunciation by speakers from China, Chang (2001) provides a list of vowels and consonants that are problematic among Chinese speakers and also cover the suprasegmental features of Chinese speakers. Ho (2003) summarizes the perceptions of teachers in Singapore about the most serious pronunciation of Chinese students based on thirty nine audiovisual recordings. As Ho (2003) mentioned, the pronunciation of English speakers from different regions in China is different. However, there are some features that are in common and distinguish China English from other varieties of English.

So this paper sets out to investigate the segmental features of English pronunciation of college students from Mandarin speaking regions in Mainland China, in an attempt to offer teachers teaching strategies addressing the most acute pronunciation problems among college students.

\section{PARTICIPANT}

Ten participants chosen randomly for this study are fresh students majored in English at Nanchang Business College, Jiangxi province. They are consists of 2 male and 8 female students with an age mostly in 18 and 19 years, all of them come from different provinces in the Southeastern, Eastern and Central part of China and take Mandarin as their mother tongue. Hence, they are chosen in this study for the research in whether their English pronunciation has been influenced by their L1, Mandarin Chinese, and whether their pronunciation shares similar acoustic features of English by Mandarin utterance from Mainland China. All ten participants were required to carry out the task of reading aloud a passage extracted from New Trend English Pronunciation Course by Ming-Dong Liu et al, 2018. The personal background information of ten participants can be described in Table 2 and they participated in all activities of audio data collection.

\section{MATERIAL}

All ten participants were invited to read aloud the same text extracted from a textbook named New Trend English Pronunciation and Intonation course by Liu Ming-Dong et al, published by the Commercial Press and their sound data was recorded. The following ten sentences were selected in this research as the material for in-depth analysis of participants' pronunciation features.

S1. The soul is not where it lives at present, but where it loves.

S2. She won the first prize in sailing competition, but at what price.

S3. Eat at pleasure, drink with measure, and you will become healthy.

S4. He remained loyal to the royal family after the painful revolution.

S5. But bad habits won't change without a lot of hard work, will they?

S6. The path to learning to speak a second language without an accent appears to be a combination of hard work, a good ear, and a strong desire to sound like a native speaker.

S7. You have some interesting idea in your composition, but your English needs polishing as usual.

S8. When the bell rang, the young boy ran straight out of the classroom without taking his schoolbags.

S9. Even though she is having her birthday on the fifteenth of October.

S10. We were all very worried about that old tourist in such a bad weather.

These ten sentences have been chosen because they involve some phonological features that are believed to be quite confusing ones for L1 Chinese to pronounce correctly e.g. $/ \mathrm{d} / / \theta / / \mathrm{y} / / 3 /$ etc, and the reasons why the participants mispronounced those consonant phonemes frequently.

\section{Methods}

The recordings of the ten participants have been collected and their pronunciation is analyzed in details in terms of English segmental features by acoustic phonetic software, praat (Version 6.1.14). As there are some mismatches among participants' pronunciation and the native pattern, e.g. RP and GA and some utterances are mispronounced as well. Therefore, the error analysis was employed in this research. The transcription of the text on the speakers' recording is conducted and IPA symbols are used as a measurement to check whether the participants' pronunciation is correct or not. Some features involving vowels and consonants known to be problematic for many ESL learners can be detected through this process, and similarly common phonological features can be generalized in this approach by Mandarin speakers from Mainland China. 


\section{DATA ANALysis}

The data was analyzed by identifying the mispronunciation patterns that are deviated from the correct pronunciation according to the International Phonetic Alphabet symbols and the most serious problems can be identified at the segmental level (consonants and vowels), as can be seen in Table 2 and 3:

TABLE 2

Mismatches OF THE Vowels AND THEIR FEATURES

\begin{tabular}{|c|c|c|c|}
\hline Vowels & Phrase 1 & Phrase 2 & Features \\
\hline$/ æ / \rightarrow / \mathrm{e} /$ & S5: bad habit & S8: schoolbags & Shortening of diphthong \\
\hline$/ \mathrm{ei} / \rightarrow / \mathrm{e} /$ & S2: sailing & S4: painful & Shortening of diphthong \\
\hline$/$ /৩/ $\rightarrow / \partial /$ & S7: usual & S10: tourist & Shortening of diphthong \\
\hline /eI/ $\rightarrow /$ aI/ & S8: straight & & Shifting to a similar vowel \\
\hline$/ \mathrm{e} / \rightarrow / \mathrm{\partial} /$ & S1: present & & Shifting to a schwa \\
\hline$/ \Lambda / \rightarrow / \mathrm{a}: /$ & S8: young & S3: become & Shifting to a back vowel \\
\hline $\mid æ / \rightarrow / \Lambda /$ & S8: rang & S8: ran & Shifting to a similar vowel \\
\hline
\end{tabular}

In Table 2, "S1,S2...S7" are adopted respectively representing "Sentence 1, Sentence 2 to Sentence 7" as already shown in material part. We can also find in Table 2 the most salient feature in terms of vowel can be the substitution of

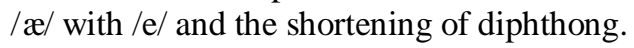

TABLE 3

Mismatches OF The CONSONANTS AND THEIR FEATURES

\begin{tabular}{|c|c|c|c|}
\hline consonants & Phrase 1 & Phrase 2 & Features of mismatch \\
\hline$/ \mathrm{d} / \rightarrow / \mathrm{d} /$ & S5: they & S9: though & Producing a similar sound in Chinese \\
\hline$/ ð / \rightarrow / z /$ & S5: without & S10: weather & Substituting a similar sound in Chinese \\
\hline$/ \theta / \rightarrow / \mathrm{s} /$ & S6: path & S9: birthday & Substituting a similar sound in Chinese \\
\hline$/ 3 / \rightarrow / r /$ & S3: treasure & & Substituting with a retroflex sound \\
\hline$/ 3 / \rightarrow / z /$ & S7: usually & & Substituting with a voiced alveolar fricative / $/$ / sound \\
\hline$/ \mathrm{J} / \rightarrow / \mathrm{s} /$ & S7: polishing & & Producing a similar sound in Chinese \\
\hline$/ \mathrm{y} / \rightarrow / \mathrm{n} /$ & S8: rang & & Producing a similar sound in Chinese \\
\hline$/ \mathrm{z} / \rightarrow / \mathrm{s} /$ & S2: prize & S7: composition & Substituting with a voiceless alveolar fricative sound \\
\hline$/ 1 / \rightarrow / \mathrm{n} /$ & S4: loyal & S6: language & Substituting with a voiced alveolar nasal sound \\
\hline
\end{tabular}

In Table 3, "S1,S2...S7" are adopted respectively representing "Sentence 1, Sentence 2 to Sentence 7" as already shown in Material part. We can also find in Table 2 the most salient feature in terms of consonants can be the substitution of dental fricative using similar sounds in Chinese and the difficulty in discerning $/ \mathrm{n} /$ and $/ \mathrm{y} /$, etc. Chinese has a set of sounds that are similar to English $/ \mathrm{J} /$, but it is not quite the same, There is nothing in Chinese that even similar to $/ \theta /$ or $/ ð /$ with their 'inter-dental' or tip of tongue flat against edge of teeth articulation.

\section{FINDINGS}

\section{A. Replacement with a Similar Sound}

Among the pronunciation with the most mistakes for L1 Chinese of English learners, dental fricative sounds $/ \theta /$ and $/ ð /$ would be the ones that is fairly problematic for most of the participants. According to the recording of speech sound, most participants had frustration in pronouncing the correct sound of voiceless dental fricative $/ \theta /$ and its voiced counterpart /ð/, they adopting frequently the substitution strategy to do with a similar sound in Mandarin Chinese e.g. /s/ to substitute for the voiceless dental fricative sound $/ \Theta /$ in English. The voiced alveolar stop /d/ and voiced alveolar fricative /z/ become the most common substitution for the voiced dental fricative sound /ð/, since these sounds are originated from Hanyu Pinyin. This findings is in agreement with Ho (2003, p. 144). Chang (2001) also pointed out that it is a shared problem among Mandarin Chinese speakers as both the / $\mathrm{\Theta} /$ and /ð/ sounds do not occur in Chinese. Besides, Ho (2003) also stated the fact that "there is a si in the Chinese pinyin transcript but not the voiceless $/ \theta /$ ".

The English consonant sounds that cannot be matched in Chinese speech sound also include voiced palatal fricative /3/ and voiced velar nasal /y/, where participants in this study tend to use voiced alveolar fricative /z/ and voiced alveolar nasal /n/ respectively as their substitution, e.g. the word usually /'ju..zu.ə.li/ is uttered as /'ju:.zu.ə.li/ and the word English/'inglif/ is pronounced as /'inglif/. 
Whereas for the vowels, there is no counterpart /æ/ sound in Mandarin Chinese, as Chang (2001) stated. It poses a great challenge to learn the phonetics of this sound for beginners learning English, especially adult learners. The participants in this study, therefore would naturally adopt the vowel /e/ as a substitution for /æ/.

This is because there are lots of differences between the Chinese phonological system and the English counterpart, so there are no exact and corresponded sounds of these phonemes that can be matched in Mandarin Chinese. For this reason, the speakers usually find another similar sound in their native language for easier pronunciation of these phonemes (Hockett, 1972; Lado, 1957).

\section{B. Failure to Distinguish between Voiceless Consonants and Voiced Consonants}

As one of the most important foreign language in China, English is a greatly important course and also a necessary communication skill for Chinese students since they enter primary school. However, most of the college students who have learned English for more than six years are still confused by the distinction between the voiced and voiceless consonants when pronouncing English. For example, they would substitute voiced alveolar fricative /z/ with its voiceless counterpart /s/ in pronouncing as the word example or use voiced alveolar nasal /n/ as a substitution for voiced alveolar liquid /l/ in the pronunciation of the word language. Therefore, this particular feature of English pronunciation is very common among Mandarin speakers in Mainland China.

The phenomenon mentioned above is due to the fact that L1 Chinese learners tend to transfer divert some of the sounds in Mandarin Chinese to English pronunciation for the ease of articulation and utterance. Nevertheless, this negative practice affects their correct pronunciation in English utterance and lead to phonological features of acoustic problems that are peculiar to Chinese learners.

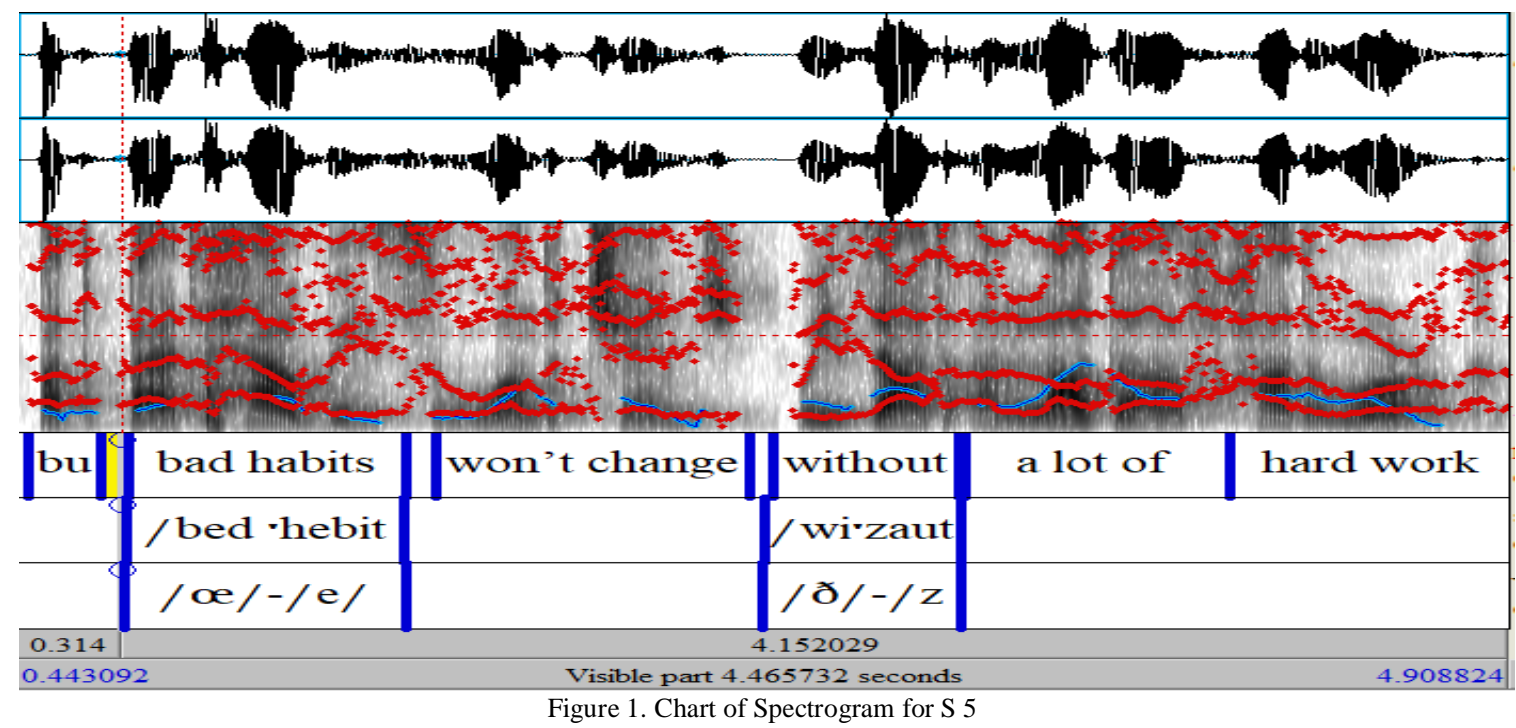

In Fig.1, there are three tiers on the chart of spectrogram, the first one is the original sentence already shown in the material, the second is the recording sounds produced by participant and the third tier shows variations between the NE and the mismatches, Fig 1 shows that in the phrase bad habits, the front vowel /æ/ was pronounced as front vowel /e/ and the voiced dental fricative /ð/ in the word without was pronounced as voiced alveolar fricative /z/.

\section{Shortening the Diphthongs}

The case of shortening the diphthongs also occurs frequently in this reading aloud test. Examples can be found in the substitution of /eI/ with /e/. This is because of the fact that the utterance of diphthongs in Chinese is usually shorter and it needs smaller tongue and lip movement than their English counterparts. As a result, in mainland China English learners from Mandarin speaking areas often mismatch of pronouncing the sounds of diphthongs as short as monophthongs, and it is without adequate distinction between the two component vowels (Chang, 2001). 


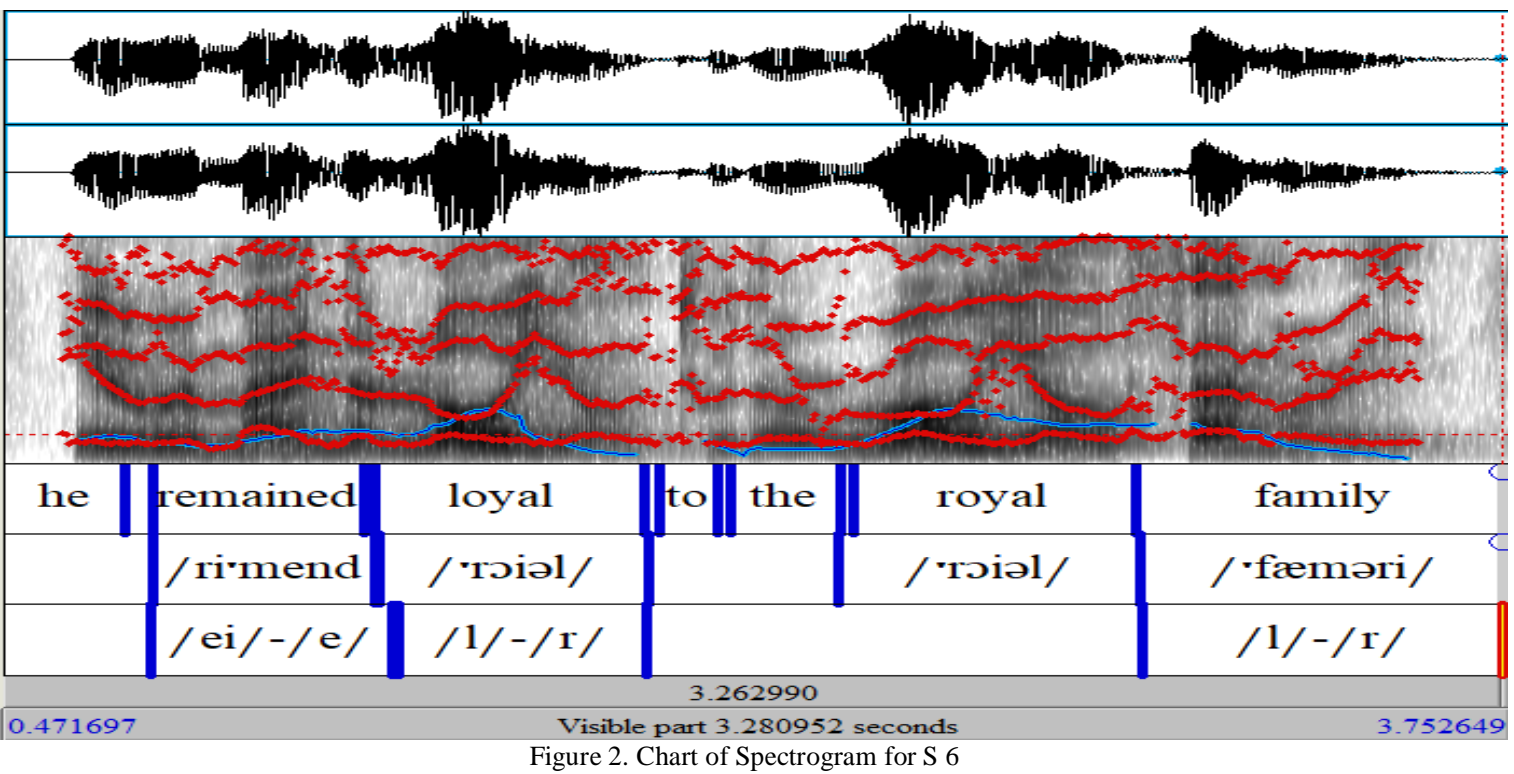

Fig. 2 shows that in word remained, the diphthong /ei/ was pronounced as single front vowel /e/, the voiced alveolar liquid / / was substituted obviously by the retroflex /r/ in the words loyal and family.

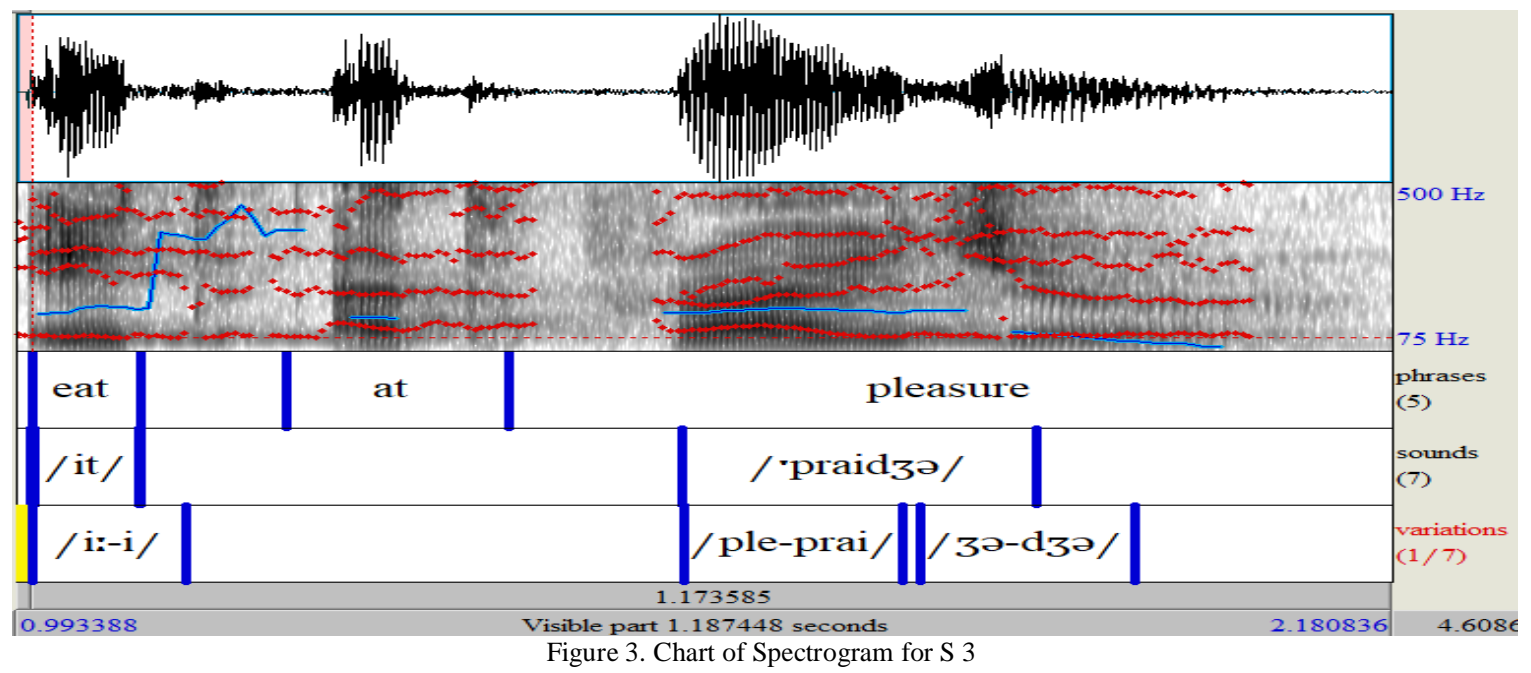

In Fig.3, the long vowel /i:/ in the word eat was pronounced as short vowel /i/, word pleasure was pronounced as /praidzə/, while in Fig.4, the sound /mezə/ was pronounced as /meidzə/ for the word measure.

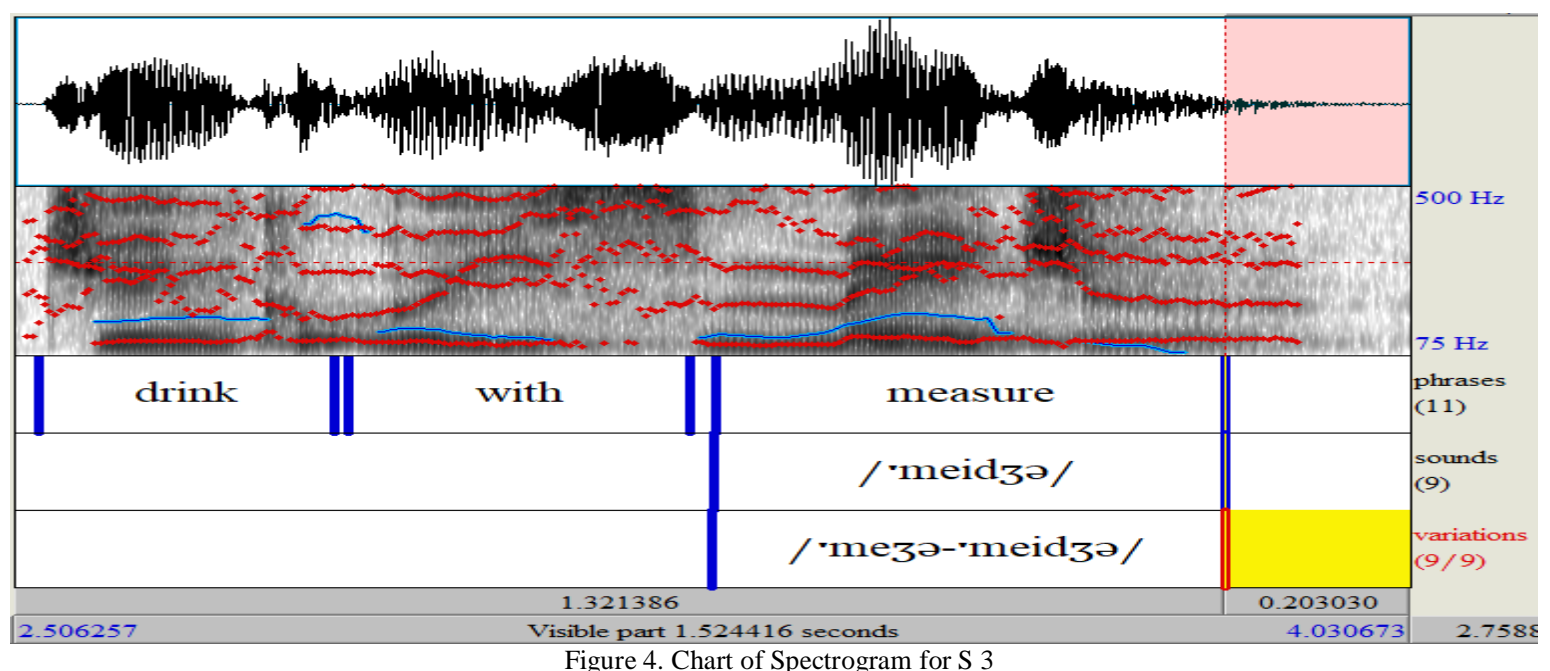




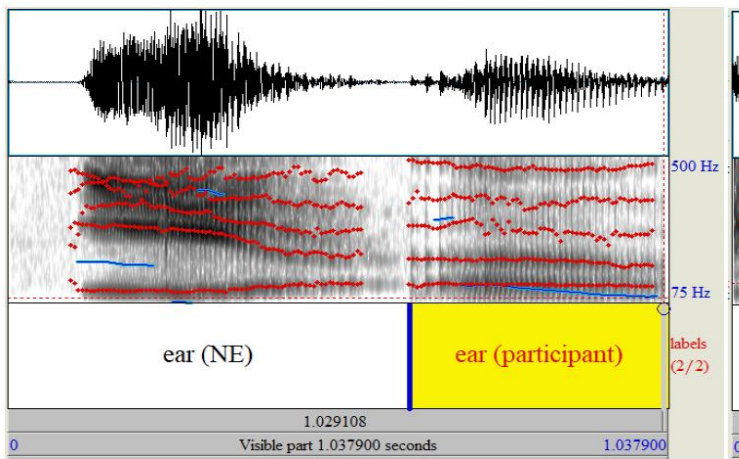

Figure 5. Chart of Spectrogram for word ear

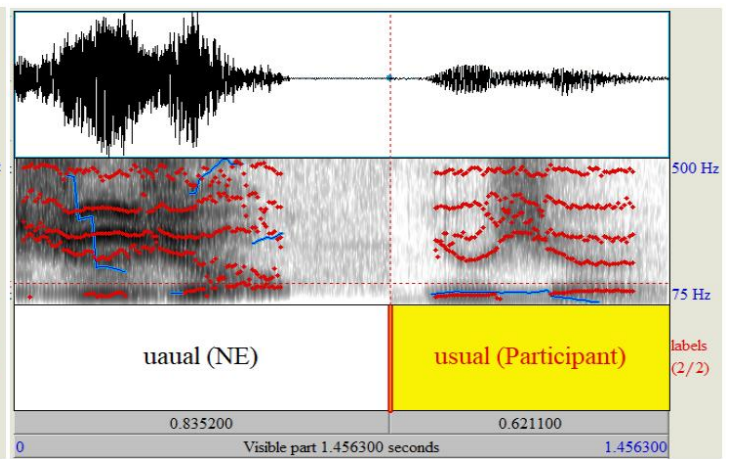

Figure 6. Chart of Spectrogram for word usual

Fig.5 and Fig.6 are chart of spectrograms for the utterance of word ear and usual produced by native English speaker (NE) and the research participant, for the word ear, the diphthong /ıə/ was pronounced as /eə/, and in Fig.6. the word usual was pronounced as /'ju:.zu.ə.li/, mismatched its original sound /'ju:.zu.ə.li/.

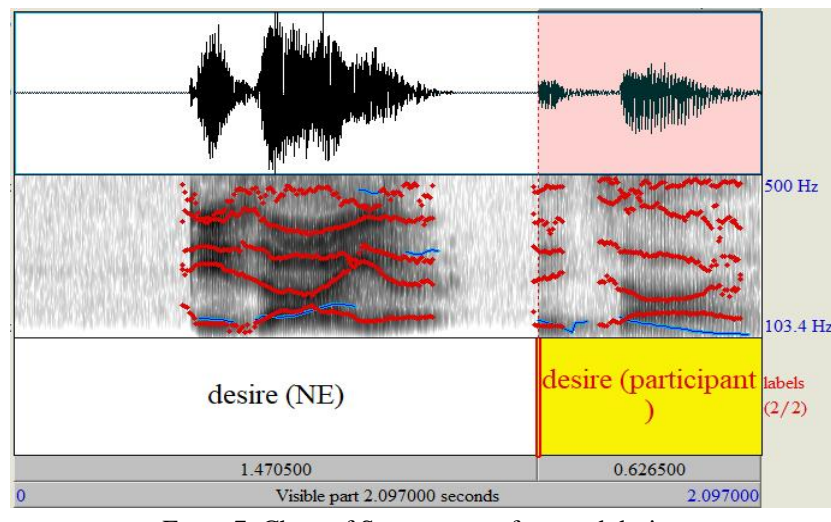

Fgure 7. Chart of Spectrogram for word desire

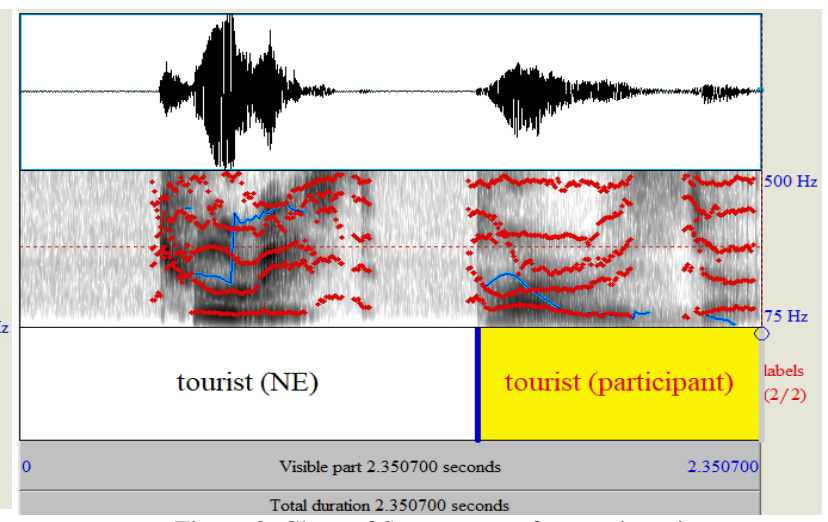

Figure 8. Chart of Spectrogram for word tourist

In Fig.7. the word desire was pronounced as /d' zaiə(r)/, mismatched its original sound /dı'za:ə(r)/, and in Fig.8. the original sound /'toərist/ for tourist was pronounced as /'təorist/. All of four words are extracted from S6, S7, S6 and S10 respectively, errors of pronunciation can be told apart clearly from the spectrograms chart and distinctions between F0, $\mathrm{F} 1$, intensity and duration of vowel can also be clearly identified.

\section{Pedagogical IMPliCATION AND APPLICATIONS FOR TEACHING}

This study aims at identifying the most problematic sounds with English segmental features by Mandarin speakers, and realizing the perception of teachers the most obvious pronunciation problems among Mandarin Chinese speakers. Furthermore, teaching and remedial instructions of these peculiar phonemes are also suggested in the hope of aiding students to pronounce sounds of words more effectively as well as correcting their mismatches. Therefore, the strategies adopted to improve Mandarin speakers' comprehensibility and their perception in English phonetics are highly-valued.

Pronunciation pattern drills could be adopted in order to deal with English pronunciation problems and to correct and improve the mismatches effectively. As Ho (2003, p. 149) stated, there are several useful strategies suggested by teachers in the CELC (Center for English Language Communication), in his study, e.g. teaching strategies are listed such as providing explicit phonetic instruction on the places and manners of articulation, encouraging students to identify errors of speech sounds, incorporating funny poems, drama into the articulation exercises to make pronunciation teaching meaningful and memorable and offering tongue-twisters exercises for students to teach them difficult sounds, etc. All these strategies help students pronounce English sound correctly and get awareness of comprehensibility of communication.

In this paper, the researcher will provide a kind of pronunciation teaching method focus on difficult sounds such as $/ \Theta /$ and /ð/ etc and teachers should provide students explicitly the manners and places of articulation. This explicit teaching strategy help students acquire a clear and concrete perception how the sound is actually pronounced, consequently, it would be easier for them to imitate and memorize the correct pronunciation as well. Moreover, lists of words that contain the various phonemes could be chosen as speech sound materials for students to discriminate between the correct sound and the similar sound which is pronounced by many Chinese students for substitution. For example, the "then/ ðen/" and "zen/zen/" and the "sink/siy/" and "think/ery/". By contrasting the differences of pronunciation, students will come to realize the fact that whether they normally utterance is deviated from the correct pronunciation in accordance with the International Phonetic Alphabet symbol. Therefore, they can be trained a 
perception of whether their own pronunciation is correct or not. After that, students can obtain the comprehensibility of correct sound that teachers are reading aloud to them. At later stage, students are demanded to do some production tasks e.g. making a dialogue in pair work and being aware of the proper pronunciation of the target words that contain $/ \mathrm{\Theta} /$ and $/ ð /$. By doing so, students can be trained to have a better perception of these peculiar sounds and therefore improve their phonetic accuracy of the difference sounds (e.g. / / / and /ð/ etc) among Mandarin Chinese students.

For other students that have already fossilized this mistake, remedial instruction can be adopted by asking students "resetting your tongue on your teeth" and showing tongue position with diagrams.

\section{CONCLUSION}

In conclusion, this study has achieved its aim to examine the specific pronunciation mismatches in terms of segmental level among Mandarin speakers from different parts of China. The findings was well corresponded with the most obvious English segmental features among Mandarin Chinese speakers, such as use of substitution of $/ \mathrm{s} /$ for $/ \mathrm{e} / \mathrm{d} /$ or /z/ for /ð/ that appear very common among the errors made by Mandarin Chinese speakers. In terms of the phonological feature of vowels, the shortening of diphthongs, e.g. from /eI/ to /e/ is also very common for Mandarin speakers for greater ease in pronouncing words. According to this, the pedagogical implication and applicable suggestions were offered to English pronunciation teaching and some serious problems of English pronunciation are focused to deal with by speakers from Mandarin speaking regions in mainland China. In future studies, it is hoped that both the reading aloud tasks together with interviews will be adopted to examine the pronunciation problems when speakers' utterance in both controlled and authentic speech environment. In addition to this, the participants from Cantonese regions could also be involved in the study to examine whether their mismatches of some English pronunciations could also be due to the influence of Mandarin Chinese and in an attempt to identify the differences between English pronunciation features by speakers from Mandarin and Cantonese speaking regions in Mainland China.

\section{REFERENCES}

[1] Avery, P. \& Ehrlich, S. (1992). Teaching American English pronunciation. Oxford: Oxford University Press.

[2] Chang, J. (2001). "Chinese speakers". In M. Swan and B. Smith (Eds.), Learner English: A teacher's guide to interference and other problems. 310-324. Cambridge: Cambridge University Press.

[3] Derwing, T. M., Munro, M. J., and Wiebe, G. (1998). Evidence in Favor of a Broad Framework for Pronunciation Instruction. Language Learning, 48 (3), $393-410$.

[4] Ho, Aichen T. "Intonation Variation in a Mandarin Sentence for Three Expressions: Interrogative, Exclamatory and Declarative." Phonetica 34 (1977): 446-457.

[5] Hockett, C. F. (1972). Learning pronunciation. In Croft (Ed.), Reading on English as a second language. Cambridge, MA: Winthrop Publishers, Inc. 147-150.

[6] Lado, R. (1957). Linguistics across cultures. Ann Arbor: The University of Michigan Press.

[7] Mindong Liu et,al. (2018) New Trend English Pronunciation and Intonation course, Beijing, the Commercial Press 49-75

[8] Ohata, K. (2004). Phonological differences between Japanese and English: Several potentially problematic areas of pronunciation for Japanese ESLEFL learners.138-157

[9] Swan, M. \& Smith, B. (1987). Learner English: A teacher's guide to interference and other problems. Cambridge: Cambridge University Press.

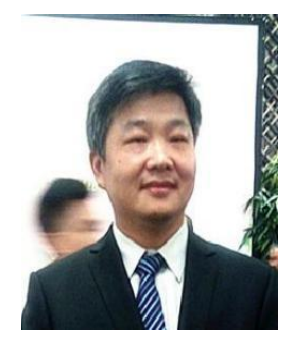

Chao Wu was born in JiangXi province China in 1966. HE received his Master's degree in English Language and Literature from JiangXi Normal University, China in 2009. He is currently a professor in NanChang Business College, JiangXi Agricultural University, Jiangxi, China. His research interests are speech production and perception, L2 pronunciation and intelligibility, L2 oral assessment and testing.

$\mathrm{He}$ is currently a teacher at Foreign Language Department of Nanchang Business College, JiangXi Agricultural University. He was a former Dean of the Department of Foreign Languages in Nanchang Institute of Technology (NIT), he published a book titled "Practical Business English Conversation" (Nanchang, Jiangxi: Higher Educational Press, 2008) which gained the first prize as "Jiangxi Excellent Textbook of Higher Education",

Prof. Wu is a member of Jiangxi English Society at present.

Qiufeng Pan was born in Jiangxi province, China in 1983, he is a Ph.D Candidate in Jiangxi University of Financial and Economics and currently he is director of Teaching Affairs Dept in Nanchang Business College, Jiangxi Agricultural University, His research interests include econometrics and statistics. He finished a Science and Technology Project of Jiangxi Province, "Development and Application of Investor Sentimental Valuation System Based on Internet Technology" project number: GJJ171479

Daiyue Cao was born in 1996, right now she is an English lecturer in Nanchang Mengchong Education Consulting Co., Ltd. Her interests are L2 acquisition and teaching methodology. 